\title{
Absence of Sensory Neurons before Target Innervation in Brain- Derived Neurotrophic Factor-, Neurotrophin 3-, and TrkC-Deficient Embryonic Mice
}

\author{
Daniel J. Liebl, ${ }^{1}$ Lino Tessarollo, ${ }^{2}$ Mary Ellen Palko, ${ }^{2}$ and Luis F. Parada1 \\ ${ }_{1}^{1}$ Developmental Biology Center, University of Texas Southwestern Medical Center, Dallas, Texas 75235-9133, and \\ ${ }^{2}$ Advanced Bioscience Laboratory-Basic Research Program, National Cancer Institute-Frederick Cancer Research \\ and Development Center, Frederick, Maryland 21701
}

\begin{abstract}
Gene-targeting experiments of Trk receptors and neurotrophins has confirmed the expectation that embryonic sensory and sympathetic neurons require neurotrophin function for survival. They have further revealed correlation between a specific neurotrophin requirement and eventual sensory modality. We have analyzed embryonic and neonatal mice with mutations in the BDNF, neurotrophin 3 (NT-3), and TrkC genes. Our data confirm an unexpectedly high proportion of sensory neuron losses in NT-3 (>70\%), BDNF (>20\%), and TrkC (>30\%) mutants, which encompass populations thought to be NGF-dependent. Direct comparison of TrkC and NT-3 mutants indicates that only a subset of the NT-3-dependent neurons also requires TrkC. The
\end{abstract}

observed losses in our TrkC mutant, which is null for all proteins encoded by the gene, are more severe than those previously reported for the kinase-negative TrkC mutation, implicating additional and important functions for the truncated receptors. Our data further indicate that mature NGF-requiring neurons undergo precocious and transitory requirements for NT-3 and/or BDNF. We suggest that neurotrophins may function in creating early heterogeneity that would enable ganglia to compensate for diverse modality requirements before the period of naturally occurring death.

Key words: BDNF; NT-3; Trk; gene targeting; neurotrophins; sensory neurons
Development of the vertebrate nervous system is characterized by the generation of an excess number of neurons during embryogenesis. In the peripheral nervous system (PNS), the excess neurons disappear through a process of naturally occurring cell death after target innervation has been achieved. In the peripheral and sympathetic nervous systems, the neurotrophins have long been identified as major determinants of neuronal survival during this process (Barde, 1994). The classical neurotrophic hypothesis postulates that after target innervation, limiting amounts of the related target-derived soluble polypeptide growth factors NGF, BDNF, neurotrophin 3 (NT-3), and NT-4/5 support a subset of maturing neurons that successfully compete for the neurotrophins. In vivo application of NGF-blocking antibodies impedes embryonic sensory or sympathetic development, and application of excess exogenous neurotrophins prevents neuronal cell death in avian and rodent embryos (Angeletti and Levi-Montalcini, 1972; Johnson et al., 1980; Hamburger and Yip, 1984; LeviMontalcini, 1987). In vitro, primary culture studies from rodent and chick sensory neurons have added experimental support for this model. Immature neurotrophin-independent sensory and sympathetic neuroblasts can be maintained in culture and can be observed to progress through a maturation process (Barde, 1994;

Received April 4, 1997; revised Sept. 5, 1997; accepted Sept. 12, 1997.

D.J.L. and L.F.P were supported by National Institutes of Health Grant NS33199. L.T., M.E.P., and L.F.P. were supported by the National Cancer Institute, Department of Health and Human Services, under Contract N01-CO-4600 with Advanced Bioscience Laboratory. We are grateful to S. Reid for assistance in microinjection and S. Kharzai for assistance in histology. We thank Kris Vogel for sharing unpublished results and for critical reading of this manuscript.

Correspondence should be addressed to Dr. Luis F. Parada, Developmenta Biology Center, University of Texas Southwestern Medical Center, 6000 Harry Hines Boulevard, Dallas, TX 75235-9133. E-mail: PARADA@UTSW. SWMED.EDU

Copyright (C) 1997 Society for Neuroscience $\quad 0270-6474 / 97 / 170001-09 \$ 05.00 / 0$
Vogel et al., 1995). In addition, more recent experiments have shown that overexpression of NT-3 during chick embryogenesis can lead to disruption of normal ganglionic development (Ockel et al., 1996), and interference with NT-3 function results in reduction of sensory neurogenesis (Lefcort et al., 1996). As in the embryo, the process begins with neurotrophin-independent neuroblasts-before innervation-and proceeds to acquisition of nonspecific neurotrophin responsiveness. Fully mature neurons are characterized by requirement for a specific neurotrophin. In the PNS, the majority of mature neurons require NGF for survival.

The interactions of the NGF family of neurotrophins with neurons are mediated by the Trk receptor tyrosine kinase family (Kaplan et al., 1991; Parada et al., 1992). Three Trk-encoding genes have been identified in higher vertebrates, and their expression patterns and relative affinities to the neurotrophins concord well with the known neurotrophin requirements of distinct neuronal subpopulations (Parada et al., 1992; Barbacid, 1994). Gene targeting in mice has provided important validation of the neurotrophic hypothesis (Snider, 1994; Tessarollo et al., 1994; Snider and Wright, 1996). Both TrkA and NGF mutant mice (Crowley et al., 1994; Smeyne et al., 1994) exhibit sensory and sympathetic deficits that are consistent with the prevailing models (Klein et al., 1990; Tessarollo et al., 1993; Barde, 1994; Crowley et al., 1994; Lamballe et al., 1994). Mice deficient for TrkB and BDNF genes display a loss of sensory neurons, and mice deficient for TrkC or NT-3 have loss of proprioceptive and subsets of mechanoreceptive sensory neurons (Snider, 1994; Tessarollo et al., 1994; Snider and Wright, 1996). Analysis of double mutations has provided additional novel information. For example, BDNF and NT-3 have complementary roles in the formation of acoustic and spiral ganglion neurons, and BDNF and NT-4/5 support distinct sub- 
a

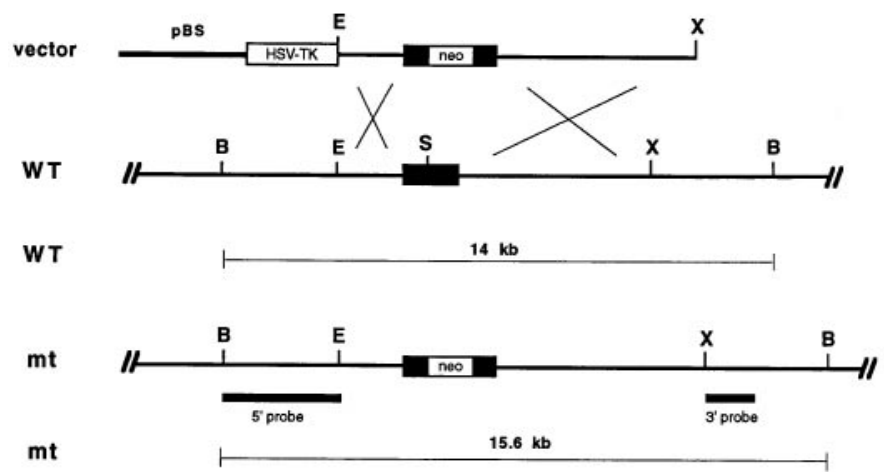

$1 \mathrm{~Kb}$

b

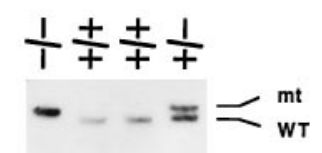

Figure 1. Generation of BDNF mutant mice. $a$, Schematic showing the replacement vector and strategy used to inactivate the BDNF gene. The filled bar indicates the BDNF coding region. Restriction enzyme sites are as indicated: $B, B g l \mathrm{II} ; E, E c o \mathrm{R} 1 ; S, S m a 1 ; X, X b a 1 . b$, Southern blot analysis of tail DNA from a litter obtained intercrossing two BDNF $+/-$ mice. $B g l \mathrm{II}$ restriction enzyme digestion and the $5^{\prime}$ external probe indicated in $a$ were used to detect rearrangement in the mouse BDNF locus. The 14 $\mathrm{kb}$ wild-type $(W T)$ and $15.6 \mathrm{~kb}$ rearranged $(m t)$ DNA bands are indicated.

populations of nodose neurons, presumably via the same TrkB receptor (Conover et al., 1995; Ernfors, 1995; Liu et al., 1995). In the present study, we have used mice targeted at the BDNF, NT-3, and TrkC genes to examine further the requirement for neurotrophins in the developmental formation of the nervous system.

\section{MATERIALS AND METHODS}

Targeting vector, electroporation, and selection. The replacement targeting vector consisted of a $7.0 \mathrm{~kb} 129 \mathrm{SV}$ (Stratagene, La Jolla, CA) mouse genomic fragment containing the single-exon BDNF-coding sequence. The пео gene with the phosphoglycerate kinase 1 promoter and the bovine growth hormone polyadenylation sequence (pGKneobpA) was introduced into a SalI site to disrupt the coding exon as a positive selectable marker (Fig. 1a). A pGK-thymidine kinase cassette was used as a negative selectable maker (Tessarollo et al., 1994). Electroporation and selection were performed using the CJ7 embryonic stem (ES) cell line as described elsewhere (Tessarollo et al., 1994). DNAs derived by G418/FIAU-resistant ES clones were screened using a diagnostic Bg1II restriction enzyme digestion using the $5^{\prime}$ and $3^{\prime}$ probes external to the targeting vector sequence indicated in Figure $1 a$. Recombinant clones containing the predicted $15.6 \mathrm{~kb}$ rearranged band were obtained at a frequency of 1 in 10.

Generation of mutant mice. Two independent targeted ES cell BDNF recombinant clones injected into $\mathrm{C} 57 \mathrm{Bl} / 6$ blastocysts generated chimeras that transmitted the mutated BDNF allele to the progeny exhibiting indistinguishable phenotypes. Breeding of two $\mathrm{BDNF}+/-$ mice gave rise to homozygous mutant mice at a frequency of $25 \%$. Subsequently, the breeding of one $\mathrm{BDNF}+/-$ mouse and one NT-3+/- mouse resulted in $25 \%$ of the offspring heterozygous for both BDNF and NT-3. Two BDNF/NT-3 double heterozygous mice gave rise to BDNF/NT-3 double homozygous mutant mice. For embryonic staging, the day of plug appearance in the female was considered embryonic day 0.5 (E0.5). Generation of TrkC mutant mice was performed as described above. The recombination cassette was designed to ablate the first coding exon, resulting in absence of protein expression, and is described elsewhere (L. Tessarollo, P. Tsoulfas, M. J. Donovan, M. E. Palko, J. Blair-Flynn, B. L. Hempstead, and L. F. Parada, unpublished data).

Histology and in situ hybridization. For histological analysis, neonatal mice were anesthetized on ice and perfused with $4 \%$ paraformaldehyde in $0.1 \mathrm{~m}$ borate buffer, $\mathrm{pH}$ 8.0. The spinal columns with attached dorsal root ganglia (DRG) were excised and post-fixed in $4 \%$ paraformaldehyde for $24 \mathrm{hr}$, whereas the heads were post-fixed in Bouin's solution [71.4\% picric acid solution $(1.2 \% \mathrm{w} / \mathrm{v}), 23.8 \%$ formalin, and $4.8 \%$ glacial acetic acid] for $24 \mathrm{hr}$ and then washed with $70 \%$ ethanol in saline for $2 \mathrm{~d}$. The tissues were dehydrated in ethanol, embedded in paraffin, serially sectioned at $5 \mu \mathrm{m}$, and stained with hematoxylin and eosin. The number of neurons was determined in blinded experiments, by counting DRG, spinal cord ventral motor neurons (VMN), trigeminal ganglia (TG), and facial motor neurons every eighth section $(40 \mu \mathrm{m})$, whereas nodose/ petrosal ganglia, geniculate ganglia, vestibular ganglia, and spiral ganglia were counted every sixth section $(30 \mu \mathrm{m})$. DRG neurons were counted at the fourth lumbar segment, and the VMN were counted between lumbar segments 1 and 3 . No correction was made for split nuclei in the direct comparison of wild-type and mutant mice. Embryos were fixed whole in Bouin's solution, embedded in paraffin, and sectioned at $5 \mu \mathrm{m}$ thickness. Counts were made every $20 \mu \mathrm{m}$ (four sections). Mean and SE were evaluated between wild-type and mutant groups, and the significance was determined by Mann-Whitney rank sum test.

In situ hybridization protocols were performed using TrkA-, TrkB-, and TrkC-specific ${ }^{35} \mathrm{~S}$-UTP-labeled probes as described previously (Martin-Zanca et al., 1990; Tessarollo and Parada, 1995). Tissue sections were counted and photographed using an Olympus Optical (Tokyo, Japan) BX50 microscope.

Immunocytochemistry and cell counting. Wild-type and NT-3 mutant mice between embryonic days 13 and 13.25 were fixed with Bouin's solution, embedded in paraffin, and serially section at $5 \mu \mathrm{m}$. The L4 DRG was stained every $20 \mu \mathrm{m}$ with hematoxylin and eosin for quantification of total cell numbers, whereas actually neurons were quantified using adjacent sections $(20 \mu \mathrm{m})$ with an antibody against peripherin (Biogenesis, Sandown, NH). Tissues processed for immunocytochemistry were quenched with $10 \%$ methanol and $0.5 \%$ hydrogen peroxidase in $10 \mathrm{~mm}$ Tris-buffered saline (TBS, pH 7.4). Tissues were permealized with $0.1 \%$ Triton X-100 and blocked with $3 \%$ normal calf serum and $1 \%$ normal goat serum. Rabbit polyclonal antibody to peripherin (1:300) was incubated overnight at $4^{\circ} \mathrm{C}$, followed by a biotinylated secondary antibody and an avidin-biotin-peroxidase complex (Vector Laboratories, Burlingame, CA). Tissues were developed with $0.05 \% 3,3^{\prime}$-diaminobenzidine tetrahydrochloride, $0.25 \%$ nickel chloride, and $0.0045 \%$ hydrogen peroxidase in TBS, dehydrated, cleared, and mounted with a mixture of distyrene, a plasticizer, and xylene. Mean and SE were evaluated between wild-type and mutant groups, and the significance was determined by Student's $t$ test.

Retrograde labeling. For DiI tracing, postnatal day 0.5 (P0.5) mutant and wild-type mice were perfused with PBS and $4 \%$ paraformaldehyde through the left ventricle. The skin was removed, and DiI crystals (Molecular Probes, Eugene, OR) were inserted into the hindlimb and axial muscles, followed by a $25-30 \mathrm{~d}$ incubation at $37^{\circ} \mathrm{C}$. The spinal columns were removed, embedded in $3.5 \%$ agar and $8 \%$ sucrose, and sectioned transversely at $200 \mu \mathrm{m}$ using a vibratome. Sections were visualized for fluorescence with the rhodamine filter and viewed on an Olympus BX50 microscope.

\section{RESULTS}

The phenotypes of newborn homozygous mutant mice in our colony are in agreement with the reported defects for the BDNF and NT-3 knock-outs (Ernfors et al., 1994a; Jones et al., 1994; Tessarollo et al., 1994; Conover et al., 1995; ElShamy et al., 1996; Fariñas et al., 1996). Both the NT-3 and BDNF null mutations confer severe neurological dysfunction on newborn pups, resulting in death within the first 2 weeks postpartum. We have analyzed neuron loss and Trk family receptor expression in sensory ganglia and motor nuclei from these single and double mutant mice. Table 1 outlines our data from neuronal counts of sensory neurons in neural crest-derived (trigeminal and DRG) and 


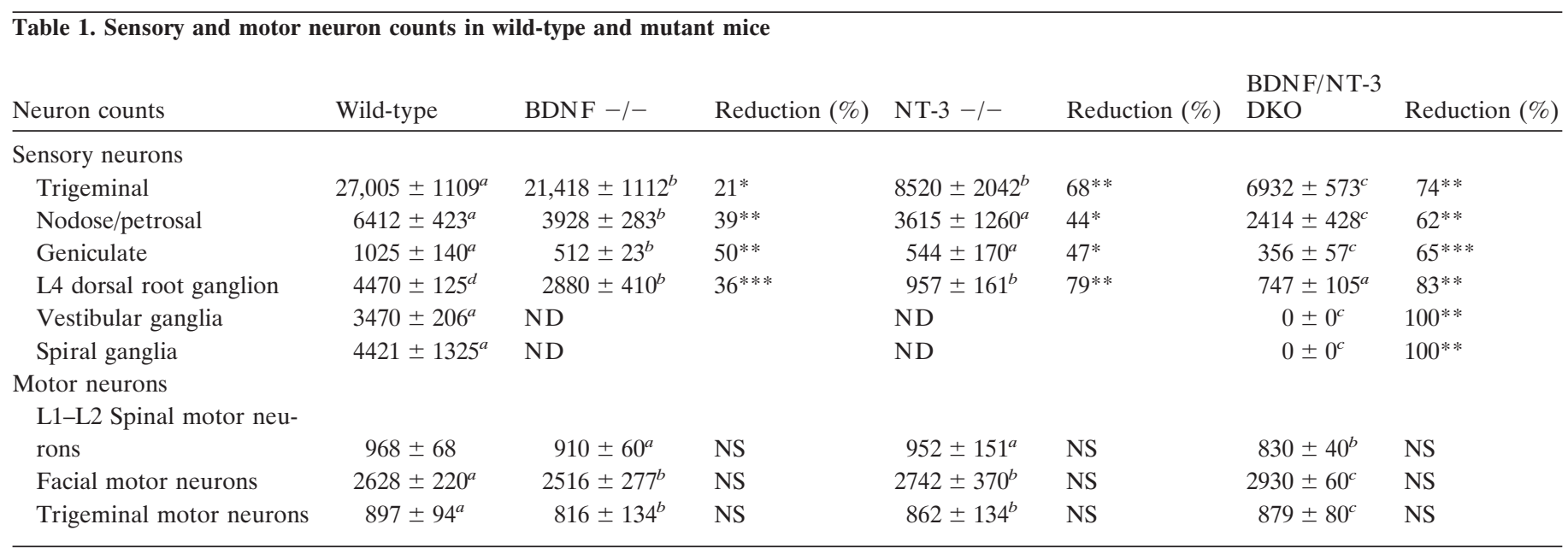

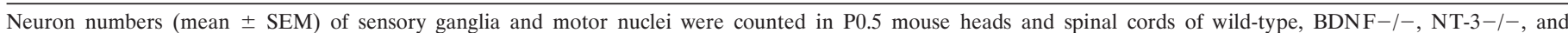

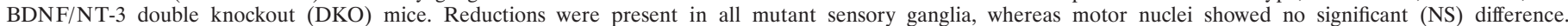
Mann-Whitney rank sum test determined the significance levels. ND, Not determined.

${ }^{a} n=3$.

${ }^{b} n=2$.

${ }^{c} n=4$.

${ }^{d} n=5$.

$* p<0.05$.

** $p<0.01$.

** $p<0.001$.

placode-derived (nodose/petrosal and geniculate) ganglia comparing wild-type newborn pups with single or double mutant pups for the BDNF and NT-3 genes (see Materials and Methods; Fig. 1).

\section{Sensory neuron losses in NT-3 and BDNF mutants}

Sensory neurons arise from two precursor populations, neural crest and epidermal placodes. Examination of neonate pups revealed substantial sensory neuron losses in both BDNF and NT-3 mutants (Ernfors et al., 1994a,b; Fariñas et al., 1994, 1996; Jones et al., 1994; Tessarollo et al., 1994; Piñón et al., 1996). In all cases, the mutant mice show a requirement for either of the two neurotrophins among a subpopulation of the ganglionic neurons, although the relative composition differed for each ganglion. For example, in the BDNF and NT-3 mutants, the trigeminal ganglion shows losses of 21 and $68 \%$ of its neurons, respectively, whereas in L4 DRG, losses of 36 and $79 \%$ were observed (Table 1).

\section{Neural crest-derived neurons}

Our previous in situ analyses of NT-3 and BDNF receptors (TrkC and TrkB, respectively) in DRG and trigeminal ganglia of wildtype embryos indicated that a minority of neurons in these ganglia could express these receptors during and after the period of naturally occurring death in lumbar DRG (after E13.5; Tessarollo et al., 1993; Valenzuela et al., 1993; Lamballe et al., 1994). In addition, the majority of neurons in mature primary cultures from trigeminal and DRG require exogenous NGF for survival. In culture, only a small percentage of the plated neurons survive in the presence of BDNF or NT-3. Neuronal counts from mutant BDNF and NT-3 lumbar dorsal root and trigeminal ganglia reveal substantially greater losses than would be predicted from these in vitro neuron survival assays (Table 1) (Ernfors et al., 1994a,b; Jones et al., 1994; Tessarollo et al., 1994; Minichiello et al., 1995; ElShamy et al., 1996; White et al., 1996) (Tessarollo, Tsoulfas, Donovan, Palko, Blair-Flynn, Hempstead, and Parada, unpublished data).
NT-3/BDNF double mutant neonates were similar in size to wild-type or single mutant littermates but died in the first postnatal day. We examined P0.5 double mutant pups by neuronal counts in several sensory ganglia (Table 1). The double mutants exhibited losses in the TG (74\%) and DRG (84\%) that were only slightly increased in comparison with the NT-3 deficient mice, indicating that the majority of BDNF-dependent neurons (21 and $36 \%$ loss in the knock-outs) must be inclusive in the subpopulation of the NT-3-dependent cells (Table 1). Thus, the in vivo requirement of embryonic sensory neurons for BDNF and NT-3 exceeds the requirement documented by primary culture studies in late-stage embryos and at birth.

To determine whether changes in receptor expression might account for the unexpectedly high neuronal losses in the mutant mice, we reexamined the proportion of ganglionic neurons that express each of the Trk family receptor mRNAs in wild-type and mutant littermates by in situ hybridization. Comparison of the data summarized in Table 1 and in Figure 2 illustrates the apparent paradox between the relatively low percentage of in vivo neurons expressing TrkB or TrkC and in vivo neurotrophin dependence on the cognate ligands BDNF and NT-3 (as determined by neuronal counts in the mutant mice). Compared with wild-type mice, the trigeminal ganglia of BDNF mutant mice have an $\sim 20 \%$ neuron reduction, which represents about half of the TrkB-expressing neurons. In the absence of BDNF and NT-3 [double knock-out (DKO)], most TrkB-expressing neurons are lost, indicating an additional requirement by these TrkBexpressing cells for NT-3. Indeed, a significant reduction in the number of TrkB-expressing neurons was observed in NT-3 mutant ganglia (Figs. 2, 3B,D). A small proportion of TrkBexpressing neurons persists in the DKO (BDNF/NT-3-/-), suggesting that these cells may express additional Trk family receptors (Fig. 3). The nodose ganglion contains neurons that require NT-4/5 specifically rather than BDNF (Conover et al., 1995; Liu et al., 1995). However, double mutant mice lacking both 
A

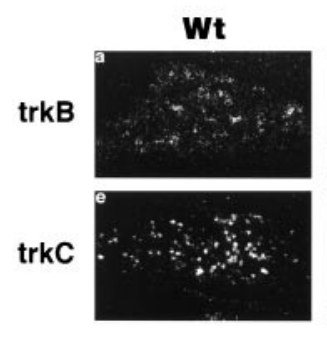

B

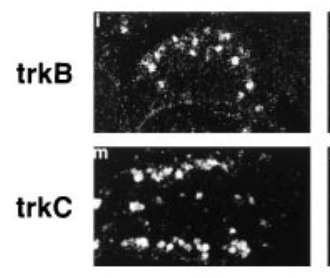

TG

BDNF $/$ -
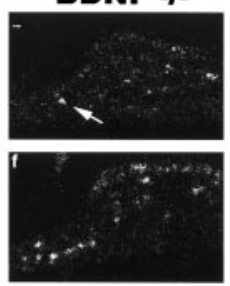
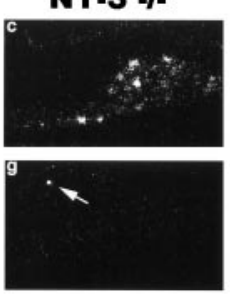

DRG
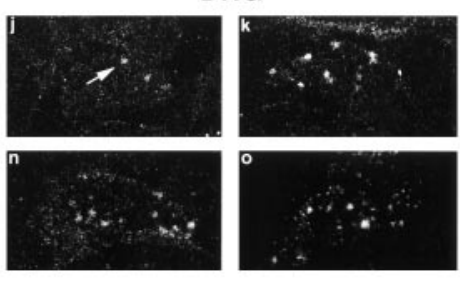

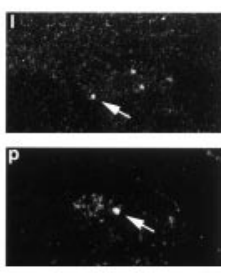

Figure 2. $\operatorname{TrkB}(A)$ and $\operatorname{TrkC}(B)$ expression in trigeminal gangila $(T G)$ and dorsal root ganglia $(D R G)$ of wild-type and BDNF and/or NT-3 mutant neonates. $q$ and $r$ show representative examples of positive and negative Trk-expressing trigeminal and DRG neurons, respectively. In $a-p$ arrows indicate small groups of TrkB- or TrkC-expressing neurons still present in mutant mice. In $q$ and $r$ black arrowheads indicate "positive" Trk-expressing neurons; white arrowheads indicate negative Trk-expressing neurons.

BDNF and NT-4/5 retained a small but reproducible number of TrkB-positive neurons ( $3 \%$; data not shown), suggesting that this small neuronal population can rely on another neurotrophin for survival (D. J. Liebl, L. Tessarollo, and L. F. Parada, unpublished data).

We next examined the expression of TrkC mRNA in the mutants. Substantial loss of TrkC-expressing neurons was observed in NT-3 mutants and in double mutant mice (Fig. 2). In DRG, we again noted a small subpopulation of TrkC-expressing neurons in the mutant ganglia, whereas the trigeminal ganglia of NT-3 and BDNF/NT-3-/- mutant mice have few if any TrkCexpressing neurons (Fig. 2).

Figure 3 indicates the proportion of newborn trigeminal and DRG neurons that express each of the Trk receptor mRNAs as a percentage of wild-type neurons (Fig. $3 A, C$ ) and as a percentage of total neurons within the mutant ganglia (Fig. 3B,D). Approximately $90 \%$ of wild-type trigeminal and DRG neurons express TrkA. This pattern is consistent with the losses seen in TrkA and NGF mutant mice (Crowley et al., 1994; Smeyne et al., 1994) as well as with the NGF requirements of primary cultured neurons (Hamburger and Yip, 1984; Barde, 1994; Vogel et al., 1995). In wild-type trigeminal ganglion, $\sim 28 \%$ of the neurons express TrkB, and 6-8\% express TrkC, whereas in DRG, $8 \%$ express TrkB, and $28 \%$ express TrkC. Again, these data are consistent with primary culture neurotrophin requirements (Vogel et al., 1995). However, comparison of these expression data with the proportion of neurons lost in the mutant mice, $21 \%$ (BDNF) and $68 \%$ (NT-3) in trigeminal and 36 and 79\%, respectively, in DRG, highlights the discrepancy between receptor expression in mature neurons and neurotrophin requirements during normal development. Examination of TrkA receptor expression in the mutant mice provided further insights (Fig. 3). Although the overall neuronal numbers are reduced in the mutant ganglia (Fig. 3B,D), the proportion of surviving neurons that express TrkA $(\sim 90 \%)$ remains essentially unchanged instead of increasing, as would be
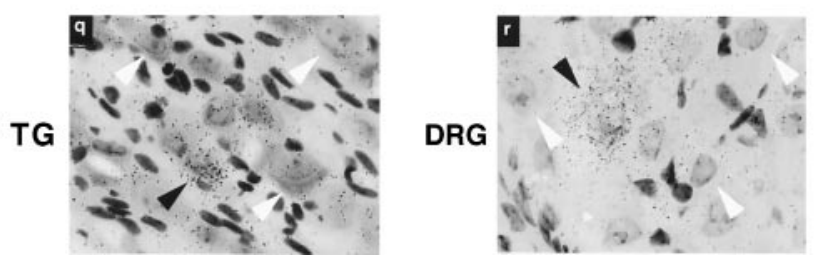

anticipated if these neurons were solely NGF-dependent. Thus $20-30 \%$ of TrkA-expressing neurons are lost in BDNF mutants, and $70-80 \%$ are lost in the NT-3 mutants (Fig. 3). These data are best reconciled by a model in which the majority (70-90\%) of neurons destined to become NGF-dependent (TrkA-expressing) undergo a phase of NT-3 and/or BDNF requirement preceding the period of programmed cell death.

To explore the developmental progression of neurotrophin requirement further, we next examined embryonic wild-type and mutant DRG from E11.5 through E15.5 (Table 2). Before E13.5, lumbar DRG primarily comprise either neurons or their precursors (Lawson and Biscoe, 1979). Therefore total cell counts reflect the status of the neuronal population in premature and mature stages and not glia. Thereafter, Schwann cells and their precursors become increasingly prominent and easily distinguishable. Thus morphological criteria (Fig. 2C) can be used to identify neurons after E13.5. Although at E11.5 we were unable to detect significant differences in total cell counts between wild-type DRG and those of single and double mutants, decreased numbers ranging from 11 to $33 \%$ became evident in each of the mutants by E12.5 (Table 2). BDNF mutants exhibited losses reaching P0 levels $(33 \%)$ by E13.5, whereas in NT-3 mutants, approximately half of the final neuronal losses seen in newborn pups occurred before E13.5.

To ascertain further that our morphological criteria for neurons and their precursors were sound, we stained serial sections of E13-13.25 L4 DRG with hematoxylin and eosin or with peripherin antisera (see Materials and Methods), a well characterized marker for neurons (Troy et al., 1990). As can be appreciated in Figure 4 by comparing sections through the largest diameter of L4 DRG, the size of the mutant ganglia (Fig. $4 B, D$ ) is reduced compared with wild-type ganglia (Fig. $4 A, C$ ), but the relative number of peripherin-positive neurons remains unchanged. Table 3 shows quantitation of these data. The results, consistent with those of Table 2, indicate a proportional reduction of total cells 
A

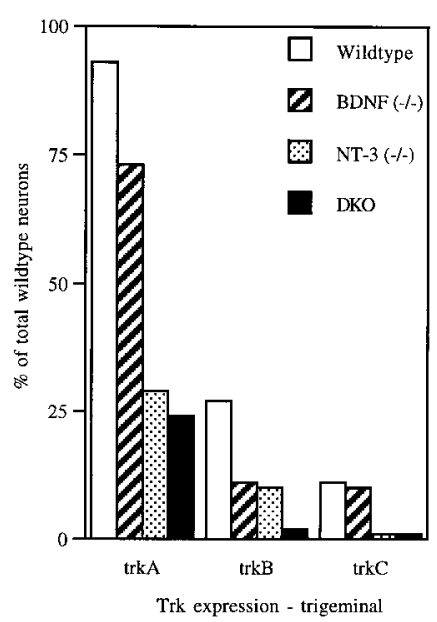

C

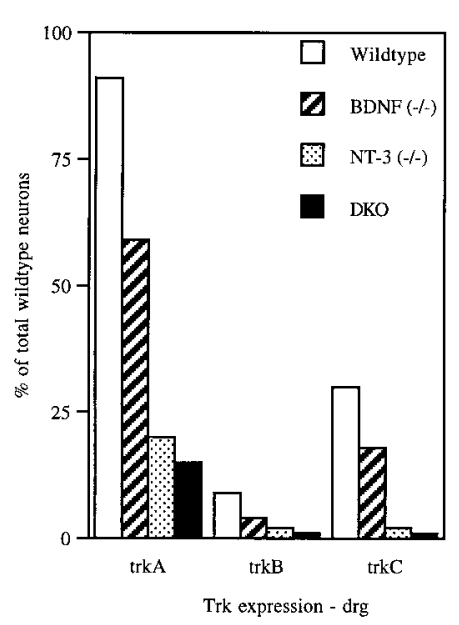

B

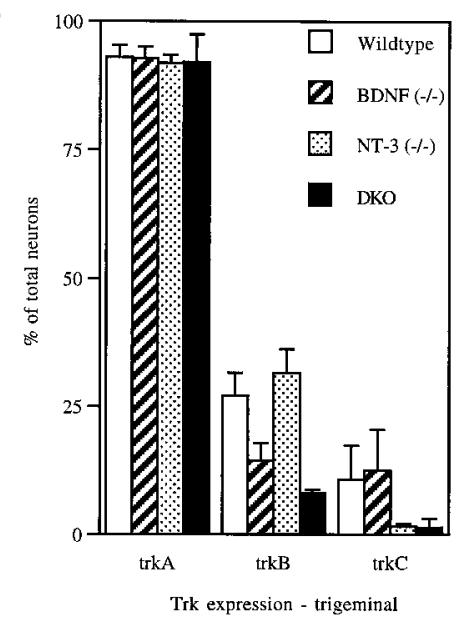

D

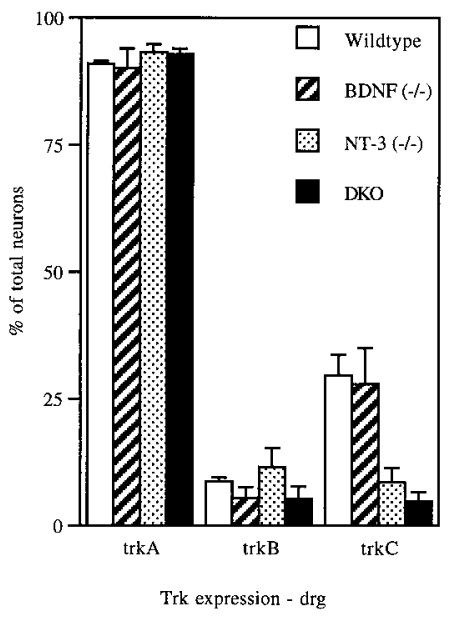

Figure 3. Quantitation of TrkA-, B-, and C-expressing neurons in the TG $(A, B)$ and DRG $(C, D)$ of neonatal mice. $A, C$, Percentage of neurons expressing Trk receptor mRNA compared with the total number of neurons present in wild-type ganglia. $B, D$, Relative percentage of neurons expressing Trk mRNA as a function of the total number of neurons in their respective ganglia. Open bar, Wild type; hatched bar, BDNF-/-; dotted bar, NT-3-/-; solid bar, BDNF/NT-3 DKO. Data and statistical analysis are from Table 1.

Table 2. DRG whole-cell counts in wild-type and mutant embryos

\begin{tabular}{|c|c|c|c|c|c|}
\hline DRG counts & E11.5 & E12.5 & E13.5 & E15.5 & $\mathrm{P} 0.5$ \\
\hline Wild-type & $5283 \pm 181^{a}$ & $9979 \pm 1285^{a}$ & $16,296 \pm 1345^{b}$ & $12,784 \pm 818^{a}$ & $4470 \pm 125^{c}$ \\
\hline BDNF mutant & $4668 \pm 486^{c}$ & $8888 \pm 291^{c}$ & $11,275 \pm 268^{b}$ & $8635 \pm 67^{a}$ & $2880 \pm 410^{d}$ \\
\hline Reduction (\%) & NS & 11 & $31^{*}$ & $32 * *$ & $36^{* * *}$ \\
\hline NT-3 mutant & $5084 \pm 486^{a}$ & $7362 \pm 823^{b}$ & $10,459 \pm 459^{b}$ & $3267 \pm 856^{a}$ & $957 \pm 161^{d}$ \\
\hline Reduction (\%) & NS & $26^{*}$ & $36^{* *}$ & $74^{* *}$ & $79^{* *}$ \\
\hline BDNF/NT-3 mutant & $4886 \pm 515^{a}$ & $6733 \pm 69^{c}$ & $8789 \pm 884^{c}$ & $2879 \pm 82^{c}$ & $747 \pm 105^{a}$ \\
\hline Reduction (\%) & NS & $33^{*}$ & $46^{* *}$ & $78^{* *}$ & $83^{* *}$ \\
\hline TrkC mutant & $5037 \pm 338^{a}$ & $7312 \pm 523^{a}$ & $11,081 \pm 1305^{b}$ & $7964 \pm 139^{a}$ & \\
\hline Reduction (\%) & NS & $27^{*}$ & $32 * *$ & $38^{* *}$ & $e$ \\
\hline
\end{tabular}

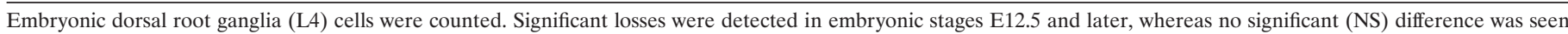
in E11.5 wild-type and mutant mice. Mann-Whitney rank sum test determined the significance levels.

${ }^{a} n=3$.

${ }^{b} n=4$.

${ }^{c} n=2$.

${ }^{d} n=5$.

${ }^{e}$ Klein et al. (1994) reported a $19 \%$ loss at P0.5 in the tyrosine kinase TrkC knock-out mutant.

$* p<0.05$.

$* * p<0.01$.

$* * * p<0.001$.

and neurons (29-34\%) in NT-3 mutant ganglia. These data support the contention that a first wave of sensory ganglion cell number reduction observed in mutant ganglia is composed at least partially of neurons and their precursors.
We have previously noted that our TrkC mutants (Tessarollo, Tsoulfas, Donovan, Palko, Blair-Flynn, Hempstead, and Parada, unpublished data) have a noticeably less severe phenotype than do our NT-3 mutants (Tessarollo et al., 1994). Although virtually 

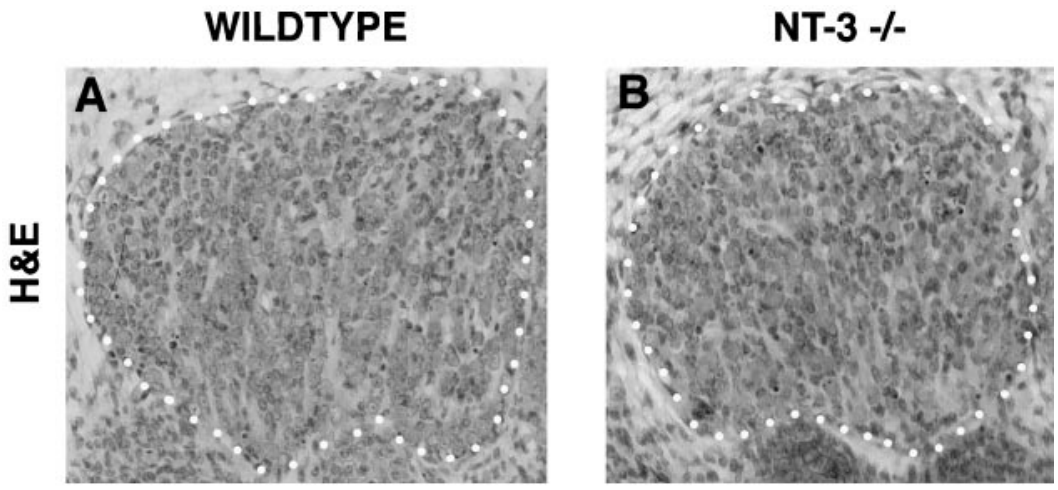

Figure 4. Analysis of peripherin-positive L4 DRG neurons of wild-type $(A, C)$ and NT-3 mutant $(B, D)$ E13-E13.25 embryos. Hematoxylin and eosin $(H \& E)$-stained sections $(A$, $B$ ) were used for quantification of total cell numbers, whereas antibodies to peripherin $(B, D)$ identified neurons. The ganglia are outlined by a dotted line.

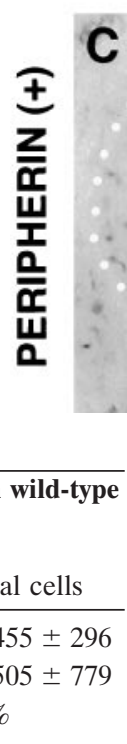

Embryonic dorsal root ganglia (L4) cells were counted in E13-E13.25 wild-type and mutant embryos. Peripherin-positive neurons represents 20 and 19\% of wild-type and NT-3-/-DRG cells, respectively. Student's $t$ test determined a significance of $p<0.005 ; n=3$.

all NT-3 mutants die within the first $24 \mathrm{hr}$ after birth, the TrkC mutants often survive for several days. Table 2 indicates that the majority of sensory neurons lost in TrkC mutants, as determined at $\mathrm{P} 0.5$, is reflected in the cell losses already present at E13.5 (Table 2). The comparison between wild type and TrkC and NT-3 mutants indicates a coincident cell loss in both mutants before E13.5, supporting the interpretation that the same subpopulation is affected. However, in contrast to the TrkC mutants, NT-3 mutants exhibit additional losses compared with wild type and TrkC mutants in morphologically distinct neurons during the ensuing $2 \mathrm{~d}$ to a final reduction in number of $\sim 74 \%$ (Table 2; also see Table 1). Given the relatively high expression of TrkC before E13.5 in sensory ganglia (Tessarollo et al., 1994), these data suggest that a subset of TrkC-expressing neurons and/or precursors coexpresses additional neurotrophin receptors that mediate rescue. In addition, these data indicate that a subpopulation of NT-3-requiring neurons that do not use TrkC as a receptor is present between E13.5 and E15.5. Thus TrkA becomes a likely candidate to mediate NT-3 signaling in this period (Barker et al., 1993; Clary and Reichardt, 1994).

\section{Proprioceptive reflex (Ia) afferents}

An additional point of interest arises from comparison of the NT-3 and TrkC mutants early in development (Table 2). Genetic ablation of neurotrophin or receptor function has been correlated with loss of specific subsets of sensory modalities (Snider, 1994; Airaksinen et al., 1996; Snider and Wright, 1996). As described previously (Fariñas et al., 1994; Klein et al., 1994; Snider, 1994; Tessarollo et al., 1994), ablation of the NT-3 or TrkC genes results in loss of Ia afferents. As illustrated in Figure 5, Ia afferents are not lost in BDNF mutants or in TrkA mutants. This observation, taken together with the data in Table 2, indicates that the Ia afferent population is generated from the pool of neurons that is coincidentally lost in both NT-3 and TrkC mutants in the first wave of cell loss before E13.5 and thus before target innervation (Fariñas et al., 1996).

\section{Placode-derived neuron loss}

We also examined sensory neurons that are placode- rather than neural crest-derived for neurotrophin requirements (Table 1). When placed in dissociated culture, nodose/petrosal ganglion neurons are primarily BDNF-dependent (70-80\%) and can be entirely supported by a combination of BDNF and NGF (K. Vogel and L. F. Parada, unpublished data). We have not detected nodose neuron responsiveness to NT-3 in primary culture, nor have we seen TrkC expression in this ganglion during mid to late development. The $44 \%$ reduction of nodose neurons seen in the NT-3-/- mutants suggests a role for NT-3 at some early period of development. Analysis of nodose/petrosal and geniculate ganglia in BDNF/NT-3 double mutants showed neuronal losses of 62 and $65 \%$, respectively. In contrast, we observed $100 \%$ loss of vestibular and spiral ganglion neurons in the BDNF/NT-3 mutants. These data are in agreement with those of Ernfors (1995) and suggest that the auditory and vestibular ganglia may be unique, having an equally divided population of neurons that depend on BDNF or NT-3.

\section{DISCUSSION}

In contrast to the TrkA and NGF mutants (Crowley et al., 1994; Smeyne et al., 1994), the proportion of sensory neurons that is 

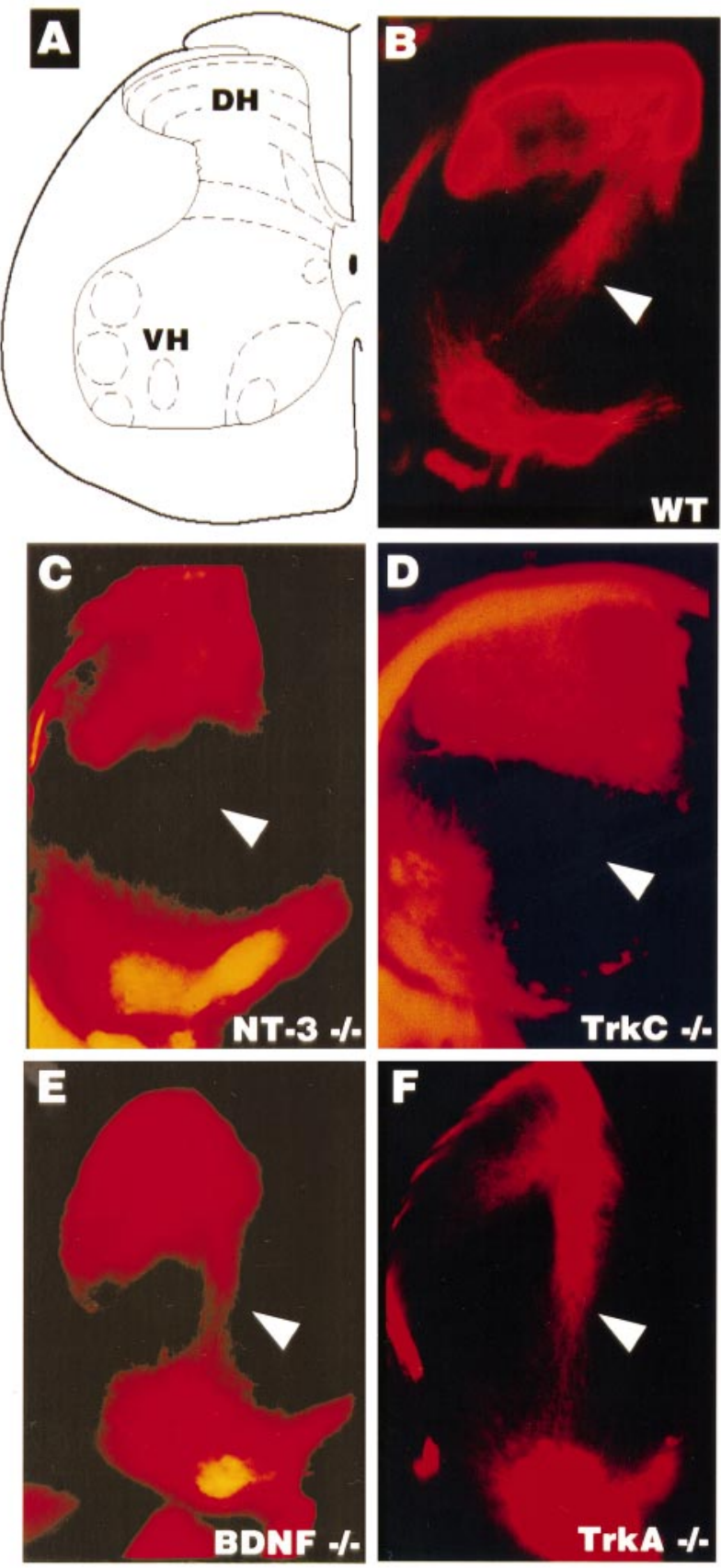

Figure 5. Ia afferents are absent in TrkC and NT-3 mutants but not in BDNF or TrkA mutants. Hemisection view of DiI (see Materials and Methods) retrogradely labeled sensory afferents and motor neurons in the P0.5 spinal cord. $A$, Schematic diagram of the spinal cord indicating the dorsal horn $(D H)$ and associated afferent laminae. The ventral horn $(V H)$ indicates where motoneuron nuclei are retrogradely labeled. $B-F$, Samples of cords from mutant pups as indicated. The arrowheads point to the location of Ia afferents.

lost in BDNF and NT-3 mutant mice exceeds the number predicted by primary culture dependence assays of embryonic neurons and by the cognate receptor expression profiles (Fariñas et al., 1994; Jones et al., 1994; Tessarollo et al., 1994; White et al., 1996). We therefore undertook this study to investigate further the steps involved in the generation of excess losses. Previous discussions of receptor and ligand phenotypes have been limited to comparisons of independently derived and analyzed mutants.
We have directly compared mutant mice derived from the same ES cell line and maintained in the same genetic backgrounds within the same vivarium. This approach permitted us to make the first developmental comparative analysis of a neurotrophin (NT-3) and its cognate receptor (TrkC), which sheds new light on the in vivo interaction of these molecules. Our studies, which use a TrkC mutation that ablates kinase and truncated isoforms (Tessarollo, Tsoulfas, Donovan, Palko, Blair-Flynn, Hempstead, and Parada, unpublished data), verifies the more severe phenotype in NT-3-/- sensory ganglia than that of its cognate receptor. In addition, we observe a twofold greater loss of sensory ganglia $(38 \%)$ in the null TrkC embryos than has been described for the kinase mutant of the receptor (19\%) (Klein et al., 1994). This marked difference is difficult to attribute to experimental variation and implicates truncated TrkC receptors as important molecules for the development and survival of sensory neuron subpopulations.

Our results are in general agreement with recent reports indicating earlier than anticipated embryonic loss of sensory trigeminal and DRG precursor and neuron losses in NT-3 mutants (Tessarollo et al., 1994; ElShamy et al., 1996; Fariñas et al., 1996). In addition, we observed substantial losses in the BDNF mutant embryos. Although direct comparison of neuronal losses between the present study and previous reports may show minor variations in absolute counts, in most cases (see below) we interpret this variance to reflect differences in tissue preparation and analysis between investigators and perhaps in genetic background differences. BDNF and NT-3 mutants each exhibit predicted sensory neuronal losses-loss of TrkB and TrkC expressing cells, respectively - as well as unexpected additional neurons, which would normally emerge as NGF-dependent. The sensory ganglia of NT-3 mutants retain only NGF and TrkA neurons but at a greatly diminished number $(20-25 \%$ of wild type). We were unable to detect significant additional losses in the TrkA and NGF population when the BDNF mutation ( $36 \%$ loss) was crossed into the NT-3 mutation (79\%). This result suggests most of the mature NGF-requiring neurons lost in the BDNF mutants are included as a subset of those lost in the NT-3 mutants.

We next examined the kinetics of cell and neuron loss in mutant ganglia by performing comparative cell counts from E11.5 through P0.5. In NT-3 mutant embryos, we observed two distinct waves of cell loss with respect to wild-type ganglia. The first wave was completed between E12.5 and E13.5 and was also observed in the TrkC mutant embryos. This period of gangliogenesis is characterized by the presence of neuronal precursors, differentiating neurons, and fully differentiated neurons (Lawson et al., 1974; Lawson and Biscoe, 1979; Sims and Vaughn, 1979). Our results are at variance with ElShamy and colleagues (1996), who report a loss of neuronal precursors but not neurons in NT-3 mutants. These workers have used a double-labeling technique for BrdU and terminal deoxytransferase in evaluating the status of their cells. Variations in observed losses may reflect subtleties in genetic background or vivarium conditions. Fariñas and colleagues (1996) have presented an elegant study of NT-3 mutants in which they propose enhanced differentiation coupled with loss of the sensory neuronal precursor pool. This mechanism, which includes loss of precursors and postmitotic neurons, would be consistent with our present results indicating two temporally separable waves of cell loss. Before E15.5, our total cell counts are consistent with these observations (I. Fariñas and L. Reichardt, personal communication). We observe a second wave of cell loss in NT-3 mutants between E13.5 and E15.5. These additional losses 
were made more evident when, in direct comparison, we were unable to detect such a significant loss in the TrkC-deficient mice. In our study, we have used peripherin as a marker for neurons (Troy et al., 1990), whereas Fariñas and colleagues (1996) used neurofilament $\mathrm{M}$ (NF-M) as a marker. Troy and colleagues (1990) have reported a comparison of peripherin and NF-M in embryonic mouse DRG. They report that NF-M stains only a subset of peripherin-positive neurons. It is therefore likely that the markers used in the two studies may account for some observed differences.

Most neuronal losses in the TrkC mutant could be ascribed to the first wave of cell loss. Thus, NT-3-dependent neurons lost after E13.5 do not use TrkC receptors and likely use an alternative receptor such as TrkA (Barker et al., 1993; Clary and Reichardt, 1994). We have verified the comparative loss between TrkC and NT-3 mutants by crossing our TrkC mutation into the NT-3 background. The dynamics of sensory neuron loss in the double mutants is indistinguishable from that of the NT-3 mutation alone, exhibiting two waves of cell loss (D. J. Liebl and L. F. Parada, unpublished data). White and colleagues (1996) have proposed aberrant induction of TrkA followed by NGF-mediated rescue as the mechanism to account for the decreased sensory neuron losses in TrkC mutants when compared with NT-3 mutants. Our data indicating two distinct waves of neuronal loss, one being coincident in single mutants or in TrkC/NT-3 double mutants, is not consistent with this model. According to White et al. (1996), the double mutants would be predicted to resemble the TrkC mutant rather than the NT-3 mutant.

As previously observed by several groups, Ia afferents are lost in TrkC (Klein et al., 1994) and NT-3 (Ernfors et al., 1994b; Tessarollo et al., 1994; Fariñas et al., 1996; Snider and Wright, 1996) mutants. The present direct comparison of Ia afferents in TrkA, TrkC, BDNF, and NT-3 mutants indicates that Ia afferents are defined by the subpopulation of cells lost before E13.5 in both the TrkC and NT-3 mutants (Fig. 5) (Tessarollo et al., 1994; Snider and Wright, 1996) and is in agreement with the results of Fariñas and coworkers (1996).

Figure 6 summarizes the outcome of our studies in DRG in which the neuronal content of a P0.5 ganglion is depicted for receptor expression (shape) and neurotrophin requirement (color). The red stippled circles are inferred to represent TrkAexpressing, NGF-dependent neuronal populations that undergo a transitory requirement for NT-3 (Tessarollo et al., 1994; Airaksinen et al., 1996; Snider and Wright, 1996; White et al., 1996) (Liebl and Parada, unpublished data). The combinatorial losses present in the BDNF and NT-3 mutants reflect the loss of additional cells that would eventually express TrkA (circles) and exhibit NGF dependence.

The classical view of naturally occurring death, once target connections in the periphery are established, imposes a dual challenge on the transitory excess population of embryonic neurons: survival of a fixed final number of neurons and selective cell reduction that preserves the appropriate numbers for each modality. In mouse sensory ganglia, the bulk of naturally occurring cell death, attributed to competition for neurotrophins during target innervation, takes place in a cranio-caudal gradient between E12 and E16 (Davies and Lumsden, 1990). The present work and other recent reports suggest a progressive developmental switching for neurotrophin requirements (Davies, 1994; Fariñas et al., 1996; Piñón et al., 1996; White et al., 1996). This interpretation is in agreement with primary culture survival studies, in which neurotrophin-switching experiments have indicated

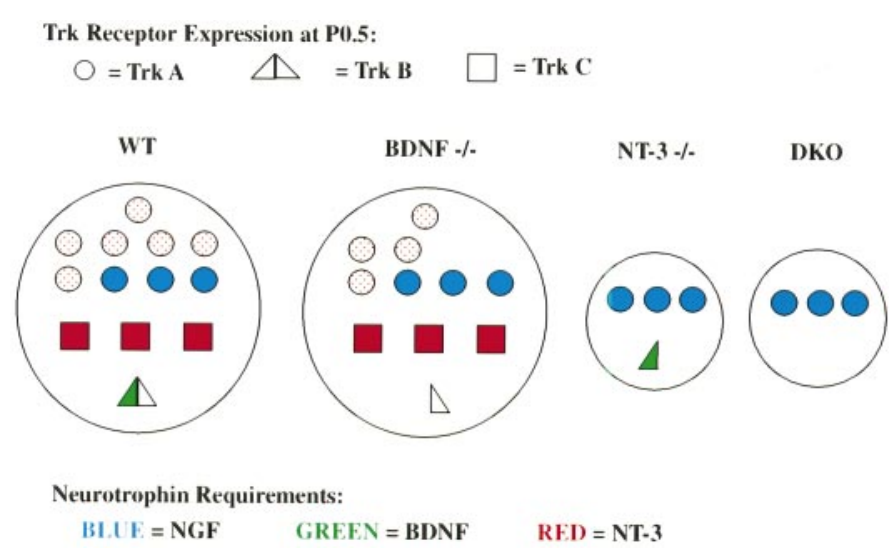

Figure 6. Schematic diagram of dorsal root ganglion neuronal subpopulations present in newborn animals as a consequence of neurotrophin knock-outs. In wild-type ganglia $(W T)$, the red stippled circles are presumed to be TrkA- and NGF-dependent neurons based on other studies (Crowley et al., 1994; Smeyne et al., 1994) and as undergoing transitory NT-3 requirements based on the present study and others (Tessarollo et al., 1994; Airaksinen et al., 1996; Fariñas et al., 1996; White et al., 1996). Shape indicates receptor type (circle, TrkA; triangle, TrkB; square, TrkC). Color indicates neurotrophin requirements (blue, NGF; green, BDNF; red, NT-3), and the relative numbers indicate approximate percentages.

a sequential requirement for NT-3 and BDNF in trigeminal neurons (Paul and Davies, 1995).

Analysis of placode-derived sensory neuron requirements for neurotrophins indicates a different process of acquisition of neurotrophin dependence from that of neural crest derived sensory neurons. For example, geniculate sensory neuron requirements for BDNF and NT-3 appear to be exclusive. This can be discerned in the double knock-outs, in which losses are essentially additive compared with the single mutants (Table 1). In contrast, the nodose ganglion appears to comprise several subpopulations of neurons, as deduced from the outcome in each of the mutants. Neuronal losses of $\sim 40 \%$ are observed when either BDNF, NT-3, or NT-4/5 is eliminated. BDNF/NT-4/5 mutants lose $80 \%$, and BDNF/NT-3 mutants lose $65 \%$. Taken together, these data indicate the existence of a small population of neurons that respond exclusively to NT-3 and a considerable population of nodose neurons that can be supported equivalently by NT-3 or BDNF. Such a neuronal population is more difficult to infer in the other ganglia we have examined.

\section{REFERENCES}

Airaksinen MS, Koltzenburg M, Lewin GR, Masu Y, Helbig C, Wolf E, Brem G, Toyka KV, Thoenen H, Meyer M (1996) Specific subtypes of cutaneous mechanoreceptors require neurotrophin-3 following peripheral target innervation. Neuron 16:287-295.

Angeletti PU, Levi-Montalcini R (1972) Growth inhibition of sympathetic cells by some adrenergic blocking agents (6-hydroxydopaminemice and rats-immunosympathectomy-chemical sympathectomysuperior cervical ganglion). Proc Natl Acad Sci USA 69:86-88.

Barbacid M (1994) The Trk family of neurotrophin receptors [review]. J Neurobiol 25:1386-1403.

Barde YA (1994) Neurotrophins: a family of proteins supporting the survival of neurons [review]. Prog Clin Biol Res 390:45-56.

Barker PA, Lomen-Hoerth C, Gensch EM, Meakin SO, Glass DJ, Shooter EM (1993) Tissue-specific alternative splicing generates two isoforms of the trkA receptor. J Biol Chem 268:15150-15157.

Clary DO, Reichardt LF (1994) An alternatively spliced form of the nerve growth factor receptor TrkA confers an enhanced response to neurotrophin 3. Proc Natl Acad Sci USA 91:11133-11137.

Conover JC, Erickson JT, Katz DM, Bianchi LM, Poueymirou WT, McClain J, Pan L, Helgren M, Ip NY, Boland P, Friedman B, Wiegand 
S, Veisada R, Kato AC, DeChiara TM, Yancopoulos GO (1995) Neuronal deficits, not involving motor neurons, in mice lacking BDNF and/or NT4. Nature 375:235-238.

Crowley C, Spencer SD, Nishimura MC, Chen KS, Pitts-Meek S, Armanini MP, Ling LH, MacMahon SB, Shelton DL, Levinson AD, Phillips HS (1994) Mice lacking nerve growth factor display perinatal loss of sensory and sympathetic neurons yet develop basal forebrain cholinergic neurons. Cell 76:1001-1011.

Davies AM (1994) Neurotrophic factors. Switching neurotrophin dependence [review]. Curr Biol 4:273-276.

Davies AM, Lumsden A (1990) Ontogeny of the somatosensory system: origins and early development of primary sensory neurons [review]. Annu Rev Neurosci 13:61-73.

ElShamy WM, Linnarsson S, Lee KF, Jaenisch R, Ernfors P (1996) Prenatal and postnatal requirements of NT-3 for sympathetic neuroblast survival and innervation of specific targets. Development 122:491-500.

Ernfors P (1995) Complementary roles of BDNF and NT-3 in vestibular and auditory development. Neuron 14:1153-1164.

Ernfors P, Lee KF, Jaenisch R (1994a) Mice lacking brain-derived neurotrophic factor develop with sensory deficits. Nature 368:147-150.

Ernfors P, Lee KF, Kucera J, Jaenisch R (1994b) Lack of neurotrophin-3 leads to deficiencies in the peripheral nervous system and loss of limb proprioceptive afferents. Cell 77:503-512.

Fariñas I, Jones KR, Backus C, Wang XY, Reichardt LF (1994) Severe sensory and sympathetic deficits in mice lacking neurotrophin-3. Nature 369:658-661.

Fariñas I, Yoshida CK, Backus C, Reichardt LF (1996) Lack of neurotrophin-3 results in death of spinal sensory neurons and premature differentiation of their precursors. Neuron 17:1065-1078.

Hamburger V, Yip JW (1984) Reduction of experimentally induced neuronal death in spinal ganglia of the chick embryo by nerve growth factor. J Neurosci 4:767-774.

Johnson Jr EM, Gorin PD, Brandeis LD, Pearson J (1980) Dorsal root ganglion neurons are destroyed by exposure in utero to maternal antibody to nerve growth factor. Science 210:916-918.

Jones KR, Fariñas I, Backus C, Reichardt LF (1994) Targeted disruption of the BDNF gene perturbs brain and sensory neuron development but not motor neuron development. Cell 76:989-999.

Kaplan DR, Hempstead BL, Martin-Zanca D, Chao MV, Parada LF (1991) The trk proto-oncogene product: a signal transducing receptor for nerve growth factor [see comments]. Science 252:554-558.

Klein R, Conway D, Parada LF, Barbacid M (1990) The trkB tyrosine protein kinase gene codes for a second neurogenic receptor that lacks the catalytic kinase domain. Cell 61:647-656.

Klein R, Silas-Santiago I, Smeyne RJ, Lira SA, Brambilla R, Bryant S, Zhang L, Snider WD, Barbacid M (1994) Disruption of the neurotrophin-3 receptor gene trkC eliminates la muscle afferents and results in abnormal movements [see comments]. Nature 368:249-251.

Lamballe F, Smeyne RJ, Barbacid M (1994) Developmental expression of trkC, the neurotrophin-3 receptor, in the mammalian nervous system. J Neurosci 14:14-28.

Lawson SN, Biscoe TJ (1979) Development of mouse dorsal root ganglia: an autoradiographic and quantitative study. J Neurocytol 8:265-274.

Lawson SN, Caddy KW, Biscoe TJ (1974) Development of rat dorsal root ganglion neurones. Studies of cell birthdays and changes in mean cell diameter. Cell Tissue Res 153:399-413.

Lefcort F, Clary DO, Rusoff AC, Reichardt LF (1996) Inhibition of the NT-3 receptor TrkC, early in chick embryogenesis, results in severe reductions in multiple neuronal subpopulations in the dorsal root ganglia. J Neurosci 16:3704-3713.

Levi-Montalcini R (1987) The nerve growth factor 35 years later [review]. Science 237:1154-1162.

Liu X, Ernfors P, Wu H, Jaenisch R (1995) Sensory but not motor neuron deficits in mice lacking NT4 and BDNF. Nature 375:238-241.

Martin-Zanca D, Barbacid M, Parada LF (1990) Expression of the trk proto-oncogene is restricted to the sensory cranial and spinal ganglia of neural crest origin in mouse development. Genes Dev 4:683-694.

Minichiello L, Piehl F, Vazquez E, Schimmang T, Hokfelt T, Represa J, Klein R (1995) Differential effects of combined trk receptor mutations on dorsal root ganglion and inner ear sensory neurons. Development 121:4067-4075.

Ockel M, von Schack D, Schropel A, Dechant G, Lewin GR, Barde YA (1996) Roles of neurotrophin-3 during early development of the peripheral nervous system. Philos Trans R Soc Lond [Biol] 351:383-387.

Parada LF, Tsoulfas P, Tessarollo L, Blair J, Reid SW, Soppet D (1992) The Trk family of tyrosine kinases: receptors for NGF-related neurotrophins. Cold Spring Harbor Symp Quant Biol 57:43-51.

Paul G, Davies AM (1995) Trigeminal sensory neurons require extrinsic signals to switch neurotrophin dependence during the early stages of target field innervation. Dev Biol 171:590-605.

Piñón LG, Minichiello L, Davies AM (1996) Timing of neuronal death in trkA, trkB and trkC mutant embryos reveals developmental changes in sensory neuron dependence on Trk signalling. Development 122:3255-3261.

Sims TJ, Vaughn JE (1979) The generation of neurons involved in an early reflex pathway of embryonic mouse spinal cord. J Comp Neurol 183:707-720.

Smeyne RJ, Klein R, Schnapp A, Long LK, Bryant S, Lewin A, Lira SA, Barbacid M (1994) Severe sensory and sympathetic neuropathies in mice carrying a disrupted Trk/NGF receptor gene [see comments]. Nature 368:246-249.

Snider WD (1994) Functions of the neurotrophins during nervous system development: what the knockouts are teaching us [review]. Cell 77:627-638.

Snider WD, Wright DE (1996) Neurotrophins cause a new sensation. Neuron 16:229-232.

Tessarollo L, Parada LF (1995) In situ hybridization. Methods Enzymol 254:419-430.

Tessarollo L, Tsoulfas P, Martin-Zanca D, Gilbert DJ, Jenkins NA, Copeland NG, Parada LF (1993) trkC, a receptor for neurotrophin-3, is widely expressed in the developing nervous system and in non-neuronal tissues. Development [Erratum (1993) 118:1384] 118:463-475.

Tessarollo L, Vogel KS, Palko ME, Reid SW, Parada LF (1994) Targeted mutation in the neurotrophin-3 gene results in loss of muscle sensory neurons. Proc Natl Acad Sci USA 91:11844-11848.

Troy CM, Brown K, Greene LA, Shelanski ML (1990) Ontogeny of the neuronal intermediate filament protein, peripherin, in the mouse embryo. Neuroscience 36:217-237.

Valenzuela DM, Masonpierre PC, Glass DJ, Rojas E, Nunez L, Kong Y, Gies DR, Stitt TN, Ip NY, Yancopoulos GD (1993) Alternative forms of rat TrkC with different functional capabilities. Neuron 10:963-974.

Vogel KS, Brannan CI, Jenkins NA, Copeland NG, Parada LF (1995) Loss of neurofibromin results in neurotrophin-independent survival of embryonic sensory and sympathetic neurons. Cell 82:733-742.

White FA, Silos-Santiago I, Molliver DC, Nishimura M, Phillips H, Barbacid M, Snider WD (1996) Synchronous onset of NGF and TrkA survival dependence in developing dorsal root ganglia. J Neurosci 16:4662-4672. 